\title{
The Exercise Physical Practice Importance as Diabetes Prevention of Type 2 Mellitus
}

\author{
Nascimento, D.B.L'; Costa, G.S ${ }^{2}$; Torres, R.L.N ${ }^{3}$; Manso, M.L.C ${ }^{4}$; Santos, P.M ${ }^{5}$; Melo, M.G ${ }^{6}$ \\ 1,2,3,4,5 Academic Baccalaureate in Nursing - ASCES-Unita; \\ ${ }^{6}$ Degree Course Lecturer in Nursing - ASCES-Unita.
}

\section{ABSTRACT}

Introduction: Type 2 Diabetes Mellitus is a chronic disease related to modern lifestyle and inactivity, accounting for $90-95 \%$ of diagnosed cases. The beginning of continuous physical practices characterized as aof form prevention for people susceptible to this type of illness. Objectives: describe how physical activity can prevent the onset of diabetes mellitus type 2. Methodology: It is an integrative review, which used articles were obtained from the data base: MEDLINE. The descriptors being used: Healthy behaviors, Type 2 diabetes, Exercise and Quality of life, using the logical AND operator. Through employee, descriptors were identified 18 publications, of which 12 were excluded for not suit the theme of the study, editorials and reviews. Being admitted the following inclusion criteria: articles published in Portuguese and English, the years 2010 to 2017. The guiding question was: how physical exercise helps in the prevention of type 2 diabetes mellitus? Results and Discussion: The items used were published one in each year, respectively: 2010, 2012, 2013, 2014 and two in 2015, which showed that physical activities with guidance and regulars contributes positively to the reduction of weight and levels of cholesterol, and is associated with significant improvements in blood pressure, the same way that adds sensitivity to insulin and therefore improves the quality of life related to health. The article 2015 reports the existence dandy cost savings with treatment as prevention reduces spending on medication.

Conclusion: It is proven that improvements in lifestyle, along with constant practice of physical exercise and low intensity prevent type 2 diabetes mellitus.

Keywords: Healthy behaviors; Type 2 diabetes mellitus; Exercises; Quality of life
*Correspondence to Author:

Nascimento, D.B.L

Academic Baccalaureate in Nursing - ASCES-Unita

How to cite this article: Nascimento, D.B.L; Costa, G.S; Torres, R.L.N; Manso, M.L.C; Santos, P.M; Melo, M.G. The Exercise Physical Practice Importance as Diabetes Prevention of Type 2 Mellitus.International Journal of Sports Medicine and Rehabilitation, $2018,1: 2$

\section{eScîPub}

eSciPub LLC, Houston, TX USA. Website: http://escipub.com/ 